\title{
Physicochemical Study and Corrosion Inhibition Potential of Ficus tricopoda for Aluminium in Acidic Medium
}

\author{
N.O. Eddy, ${ }^{a, b, *}$ P.O. Ameh, ${ }^{a}$ M.Y. Gwarzo, ${ }^{a}$ I.J. Okop ${ }^{b}$ and S.N. Dodo ${ }^{a}$ \\ ${ }^{a}$ Department of Chemistry, Ahmadu Bello University, Zaria, Kaduna State, Nigeria \\ ${ }^{b}$ Department of Chemistry, Akwa Ibom State University, Ikot Akpaeden. Mkpat Enin, Akwa Ibom \\ State, Nigeria
}

Received 24 November 2012; accepted 23 April 2013

\begin{abstract}
Gas chromatography mass spectrophotometer (GCMS) analysis of Ficus tricopoda gum indicated the presence of $4.75,56.15,32.10$ and $7.00 \%$ of camphene, sucrose, 2methylene cholestan-3-ol and 7-hexadecenal, respectively. Several stretching and bending vibrations were observed in the Fourier transformed infra-red (FTIR) spectrum of the gum. Physicochemical examinations of the gum revealed that it is pale yellow in colour, mildly acidic, ionic and display characteristics of sour taste. The solubility of the gum in water was found to increase with increase in temperature. Knowledge of the chemical constitution of the gum (hence chemical structures of its constituents) was useful in predicting the corrosion inhibition potential of Ficus tricopoda (FT) gum. Consequently, the gum was found to be a good adsorption inhibitor for the corrosion of aluminum in solution of $\mathrm{H}_{2} \mathrm{SO}_{4}$. The adsorption of the gum (which, followed first order kinetic) was found to be endothermic at FT gum critical concentration of $0.3 \mathrm{~g} / \mathrm{L}$ and exothermic at concentrations above the critical limit. The short coming of the Langmuir adsorption model in describing the existent of interaction between the molecules of the gum was complimented by the Frumkin and Dubinin-Radushkevich adsorption models. Calculated values of activation and free energies of activation indicated that the adsorption of Ficus tricopoda gum on Al surface exhibited both physical and chemical adsorption mechanism.
\end{abstract}

Keywords: corrosion, aluminum, inhibition, Ficus tricopoda gum.

\section{Introduction}

Corrosion inhibition is essential in combating the negative environmental and industrial impact of corrosion; being one of the most effective methods of

\footnotetext{
*Corresponding author. E-mail nabukeddy@yahoo.com
} 
preventing metal in petroleum, fertilizers, metallurgical and other industries, corrosion inhibition is concern with the use of chemical substances that can retard the rate of corrosion of a metal in contact with an aggressive medium [12].

Several researches have been successful in the discovery of broad ranges of inhibitors for the control of corrosion [3-5]. However, current challenges are based on utilization of inhibitors that are environmentally friendly, easy available, cost effective and biodegradable [6]. These conditions are hardly fulfilled by most inorganic inhibitors such as chromate and heavy metal rich compounds, hence current researches are directed towards the use of green inhibitors for the inhibition of the corrosion of metals [7-9]. On the list there are extracts of plant and animal and some gum exudates [10-17].

Available literature revealed that most corrosion inhibitors are chosen through knowledge of their chemical structures [18]. Generally, organic compounds that contain either hetero atoms, aromatic ring, $\pi$-electron, or long carbon chain are found to be effective corrosion inhibitors [19]. Therefore, the present study is aimed at investigating the physicochemical parameters of FT gum and its potential as a green inhibitor for the corrosion of aluminum in $\mathrm{HCl}$ medium.

\section{Materials and methods}

Samples of Ficus tricopoda (FT) gum were obtained as dried exudates from their parent trees grown at Samaru, Zaria in Sabon Gari LGA of Kaduna State of Nigeria. The outer bark of the tree was broken using a small axe. The cut was widened upward and downward and the gum formed was collected. The crude gum was purified through dissolution in cold distilled water. The solution was strained through muslin and centrifuged to obtain a small quantity of a dense gel. The straw coloured supernatant liquor obtained was separated and acidified to a $\mathrm{pH}$ of 2 with dilute hydrochloric acid. Ethyl alcohol was added until the liquor was 80 percent alcohol. The gum precipitated out was removed by centrifugation at a rate of 2000 revolution per minutes, washed with alcohol, ether and dried in a desiccator [20].

\section{Determination of physicochemical properties of the gum}

The $\mathrm{pH}$ of the gum was determined using a pre calibrated Oklon $\mathrm{pH}$ meter. The solubility of the gum was determined in cooled and hot distilled water, acetone and chloroform using the method reported by Carter [21].

\section{Corrosion studies}

Aluminum alloy sheet of composition (wt. \%, as determined by quantiometric method) Mn (1.28), Pb (0.064), Zn (0.006), Ti (0.029), Cu (0.81), Si (0.381), Fe (0.57) and $\mathrm{Al}(96.65 \%)$ was used. The sheets were mechanically pressed and cut into different coupons, each of dimensions, $5 \times 4 \times 0.11 \mathrm{~cm}$. Each coupon was degreased by washing with ethanol, cleaned with acetone and allowed to dry in the air before preservation in a desiccator. All reagents used for the study were analar grade and double distilled water was used for their preparation. 
Weight loss and hydrogen evolution experiments were carried out as reported elsewhere [18]. From weight loss measurements, inhibition efficiency, corrosion rate and degree of surface coverage were calculated using the following equations

$$
\begin{aligned}
\% I & =\left(1-\frac{W_{1}}{W_{2}}\right) \times 100 \\
\theta & =\left(1-\frac{W_{1}}{W_{3}}\right) \\
C R & =\frac{\Delta W}{A t}
\end{aligned}
$$

where $\mathrm{W}_{1}$ and $\mathrm{W}_{2}$ are the weight losses $(\mathrm{g})$ for aluminum in the presence and absence of the inhibitor, $\theta$ is the degree of surface coverage of the inhibitor, $\Delta \mathrm{W}$ $=\mathrm{W}_{2}-\mathrm{W}_{1}$, $\mathrm{A}$ is the area of the aluminum coupon (in $\mathrm{cm}^{2}$ ), $\mathrm{t}$ is the period of immersion (in hours) and $\Delta \mathrm{W}$ is the weight loss of aluminum after time, $\mathrm{t}$. In gasometric experiment, the test solution was poured into the reaction vessel. Upon the introduction of mild steel, the flask was quickly corked and the rise in volume of the paraffin due to hydrogen evolution was noted after every minute until a steady volume was observed. Inhibition efficiency was calculated as the quotient of the difference between the volume of hydrogen evolved by the blank and that of the test solution to the volume of hydrogen evolved by the blank.

\section{FTIR analysis}

FTIR analysis of the gum was carried out and that of the corrosion products (in the absence and presence of the gum) were carried out using a Scimadzu FTIR8400S Fourier transform infra-red spectrophotometer. The sample was prepared in $\mathrm{KBr}$ and the analysis was carried out by scanning the sample through a wave number range of 400 to $4000 \mathrm{~cm}^{-1}$.

\section{GC-MS analysis}

GC-MS analysis was carried out on a GC Clarus 500 Perkin Elmer system comprising of an AOC-20i auto-sampler and gas chromatograph interfaced to a mass spectrometer (GC-MS) instrument employing the following conditions: column Elite-1 fused silica capillary column $(30 \times 0.25 \mathrm{~mm}$ ID $\times 1 \mu \mathrm{M}$ df, composed of $100 \%$ dimethylpoly diloxane), operating in electron impact mode at $70 \mathrm{eV}$; helium (99.999\%) was used as carrier gas at a constant flow of 1 $\mathrm{mL} / \mathrm{min}$ and an injection volume of $0.5 \mu \mathrm{L}$ was employed (split ratio of 10:1) at an injector temperature of $250{ }^{\circ} \mathrm{C}$; ion-source temperature of $280{ }^{\circ} \mathrm{C}$. The oven temperature was programmed from $110^{\circ} \mathrm{C}$ (isothermal for $2 \mathrm{~min}$ ), with an increase of $10{ }^{\circ} \mathrm{C} / \mathrm{min}$, to $200{ }^{\circ} \mathrm{C}$, then $5{ }^{\circ} \mathrm{C} / \mathrm{min}$ to $280{ }^{\circ} \mathrm{C}$, ending with a $9 \mathrm{~min}$ isothermal at $280{ }^{\circ} \mathrm{C}$. Mass spectra were taken at $70 \mathrm{eV}$; a scan interval of 0.5 seconds and fragments from 40 to $450 \mathrm{Da}$. Total GC running time was $36 \mathrm{~min}$. Interpretation on mass spectrum GC-MS was conducted using the database of the National Institute Standard and Technology (NIST) Abuja, having more than 
62,000 patterns. The spectrum of the unknown component was compared with the spectra of the known components stored in the NIST library. The name, molecular weight and structure of the components of the test materials were ascertained. The concentrations of the identified compounds were determined through area and height normalization.

Table 1. Physicochemical properties of FT gum.

\begin{tabular}{ll}
\hline Parameters & Property \\
\hline Color & Pale- yellow \\
Odour & Sweet \\
Taste & Sour taste \\
$\mathrm{pH}$ & 4.10 \\
Percentage yield (\% w/w) & 72.00 \\
Solubility (\% w/v) & \\
$\quad$ (i) Cold water & 14.20 \\
$\quad$ (ii) Hot water & 15.10 \\
$\quad$ (iii) Acetone & 0.00 \\
$\quad$ (iv) Chloroform & 0.00 \\
$\quad$ (v) Ethanol & 0.40 \\
\hline
\end{tabular}

\section{Results and discussions}

\section{Physiochemical parameters of FT gum}

Table 1 presents the physiochemical parameters of FT gum including colour, $\mathrm{pH}$, percentage yield and solubility in various solvents. The gum is pale yellow in colour (Fig.1), it has a sour taste and a sweeten odor. The measured $\mathrm{pH}$ of the gum (4.10) revealed that the gum is acidic and is characterized with a sour taste. The solubility of the FT gum in water tends to increase with increase in temperature, indicating that the heat given off in dissolving the gum is less than the heat required to break the gum apart. The net dissolution reaction is endothermic (energy required). Therefore, addition of more heat facilitates the dissolution of the gum by providing energy to break bonds within the gums. The gum was also found to be slightly soluble in ethanol but insoluble in acetone and chloroform. The solubility of the gum in ethanol may be due to the presence of polar and non-polar ends in ethanol, which made it to dissolve some polar and non-polar compounds. On the other hand, chloroform and acetone are non-polar solvents and as expected, non-polar compounds are soluble in non-polar solvent and vice versa. Hence FT gum is ionic and it is expected to be insoluble in chloroform and acetone.

\section{GCMS study of FT gum}

Fig. 2 shows the GCMS spectrum of FT gum. From the figure it can be seen that the spectrum of FT gum is characterized with four peaks. Since the area under the GCMS peak is proportional to the concentration, results obtained from area normalization were used to estimate the percentage concentrations of identified constituents of the gum, as presented in Table 2. The table also presents the various fragmentation peaks associated with each of the fraction, the 
corresponding retention time, molar mass and chemical formula of the identified compounds. In Fig. 3, chemical structures of the identified compounds are displayed. The numbering on each of the structures corresponds to the peak number in the spectrum (Fig.2). The results obtained indicated that major components of FT gum are sucrose $(56.15 \%)$ and 2-methylene-3-ol $(32.10 \%)$, while camphene $(4.75 \%)$ and 7 -hexadecenal $(7.00 \%)$ are its minor components.

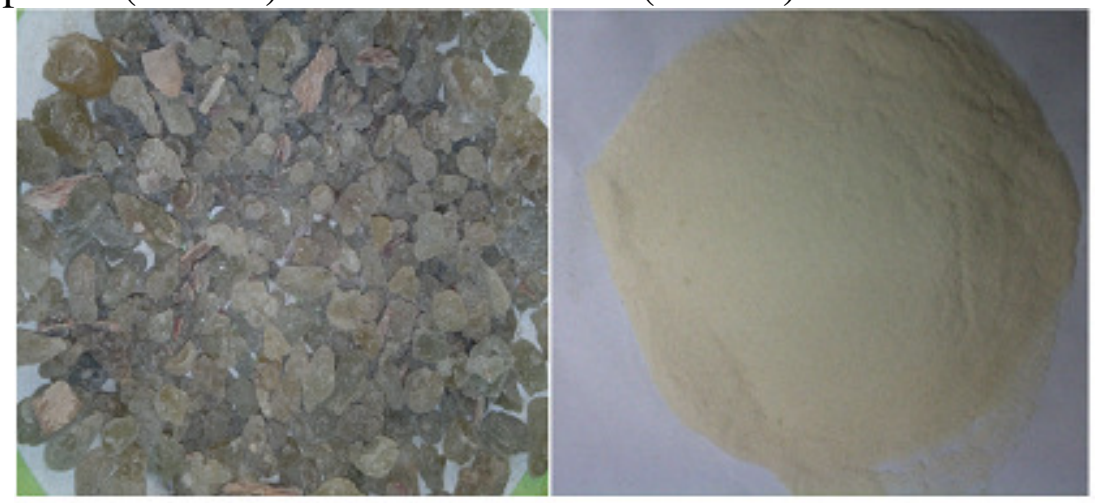

Figure 1. Samples of unprocessed and processed FT gum.

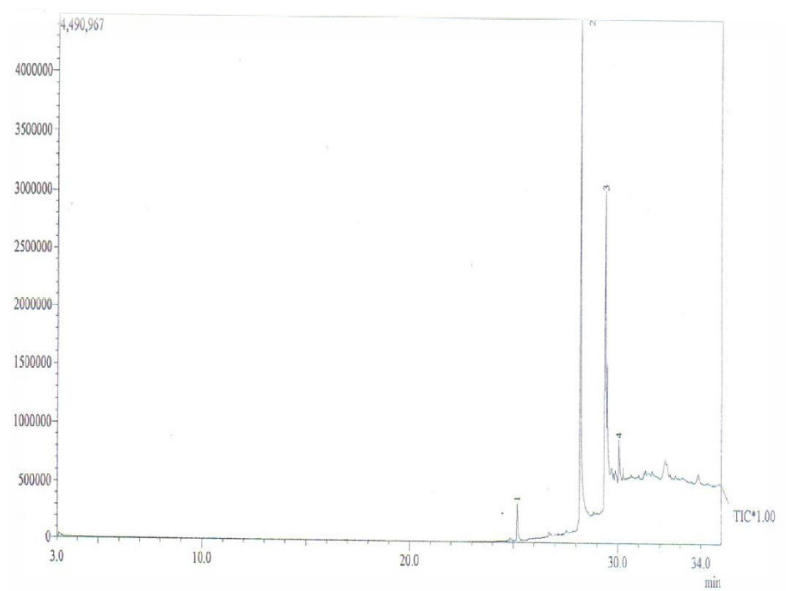

Figure 2. GCMS spectrum of FT gum.

Table 2. Characteristics of the suggested compounds identified from GC-MS gum.

\begin{tabular}{|c|c|c|c|c|c|c|}
\hline $\begin{array}{l}\text { Line } \\
\text { No }\end{array}$ & $\mathrm{C}(\%)$ & $\begin{array}{l}\text { Name of } \\
\text { compound }\end{array}$ & $\begin{array}{l}\text { Chemical } \\
\text { formula }\end{array}$ & $\begin{array}{c}\text { RT } \\
\text { (minute) }\end{array}$ & $\begin{array}{c}\text { Molar } \\
\text { mass } \\
\text { (g/mol) }\end{array}$ & Fragmentation peaks \\
\hline 1 & 4.75 & camphene & $\mathrm{C}_{10} \mathrm{H}_{16}$ & 6.1 & 136 & $\begin{array}{lcc}29(20 \%), & 42(60 \%), & 53(15 \%), \\
69(40 \%), & 77(30 \%), & 93(100 \%), \\
105(2 \%), 121(15 \%), 134 & (15 \%) .\end{array}$ \\
\hline 2 & 56.15 & sucrose & $\mathrm{C}_{12} \mathrm{H}_{22} \mathrm{O}_{11}$ & 6.4 & 342 & $\begin{array}{l}29(20 \%), \quad 41(100 \%), \quad 53(20 \%), \\
69(80 \%), \quad 77(25 \%), \quad 93(100 \%), \\
107(8 \%), 121(10 \%), 136(5 \%) .\end{array}$ \\
\hline 3 & 32.10 & $\begin{array}{l}\text { 2-methylene } \\
\text { cholestan-3-ol }\end{array}$ & $\mathrm{C}_{28} \mathrm{H}_{48} \mathrm{O}$ & 34.0 & 400 & $\begin{array}{l}55(50 \%), 71(30 \%), 88(100 \% 0 \\
101(90 \% 0,396(30 \%)\end{array}$ \\
\hline 4 & 7.00 & 7-hexadecenal & $\mathrm{C}_{16} \mathrm{H}_{30} \mathrm{O}$ & 36.2 & 238 & $\begin{array}{l}53(80 \%), \quad 65(70 \%), \quad 79(65 \%), \\
91(100 \%), 105(80 \%), 119(90 \%)\end{array}$ \\
\hline
\end{tabular}




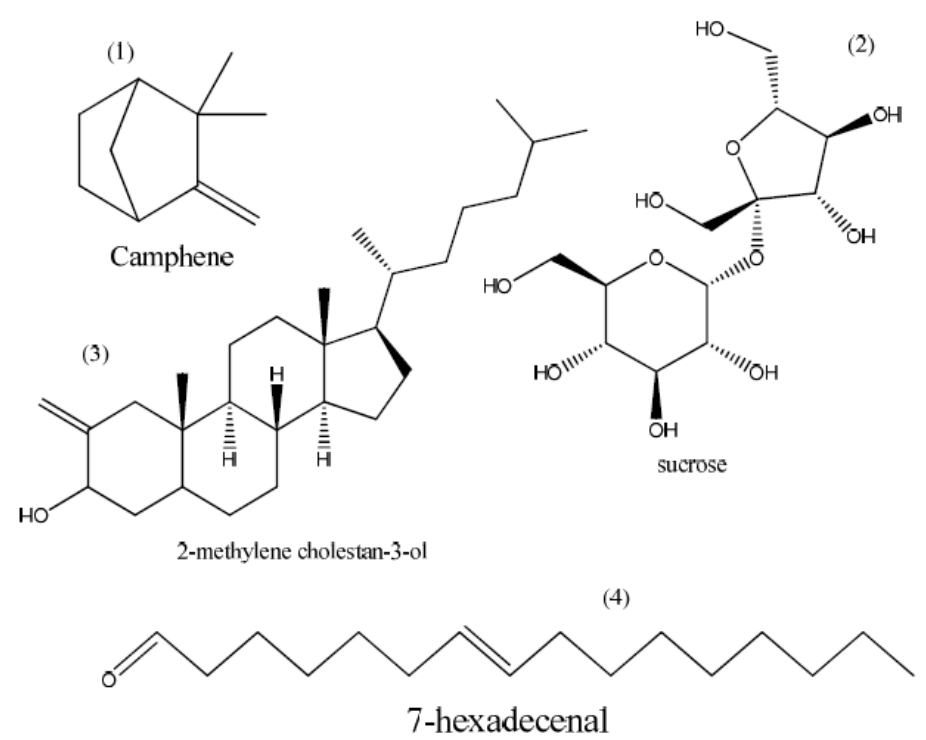

Figure 3. Chemical structures of the constituents of FT gum.

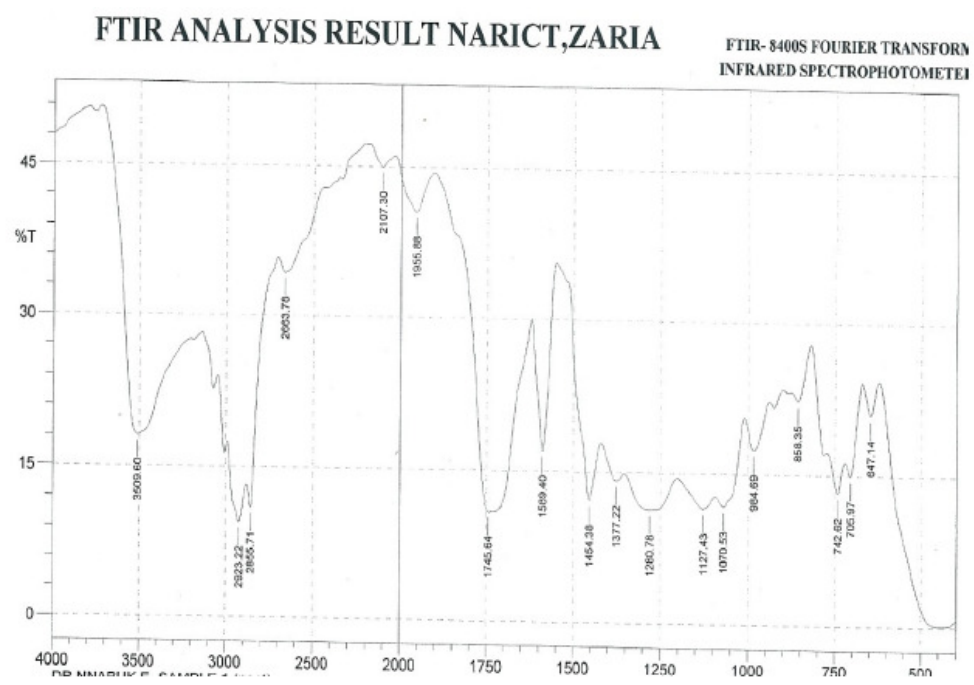

Figure 4. FTIR spectrum of $F T$ gum.

\section{FTIR}

Fig. 4 presents the FTIR spectrum of FT gum, while frequencies and peaks of IR adsorption by FT gum are presented in Table 3. A close examination of the spectra shows that there are various peaks to the right of $300 \mathrm{~cm}^{-1}$ indicating the presence of alkyl groups (in most organic compounds). A peak was also found to the left of $300 \mathrm{~cm}^{-1}$. This may be attributed to $\mathrm{C}=\mathrm{C}$ bond due to camphene or 7hexadecenal. The presence of sucrose in FT gum is correlated with the presence of cyclopentanone at $1745 \mathrm{~cm}^{-1}$ and several $\mathrm{OH}$ vibrations. $\mathrm{OH}$ stretch due to alcohol was also found at $3509.60 \mathrm{~cm}^{-1}$. This may be due to the presence of 2methylen cholestan-3-ol in the gum. C-H stretches due to alkanes were also found at 2856 and $2923 \mathrm{~cm}^{-1}$. Also at $1589 \mathrm{~cm}^{-1}, \mathrm{C}-\mathrm{C}$ stretch due to ring was also significant in the spectrum. At peak frequencies of 1454.38 and $1377.22 \mathrm{~cm}^{-1}$, $\mathrm{C}-\mathrm{H}$ bend and $\mathrm{C}-\mathrm{H}$ rock due to alkanes were observed. Several C-O vibrations were also found between the wave number range of 1071 to $1281 \mathrm{~cm}^{-1}$. Finally, 
between the wave number range of 647 and $985 \mathrm{~cm}^{-1}, \mathrm{C}-\mathrm{H}$ bend, $\mathrm{C}-\mathrm{H}$ rock and $\mathrm{C}-\mathrm{H}$ out of plane vibrations were eminent.

Table 3. Peaks and intensity of adsorption of FTIR by Ficus tricopoda gum.

\begin{tabular}{cccc}
\hline Peak $\left(\mathbf{c m}^{-1}\right)$ & Intensity & Area $\left(\mathbf{c m}^{2}\right)$ & Assignment (functional group) \\
\hline 647.14 & 21.016 & 31.693 & C-H bend due to alkene \\
705.97 & 14.986 & 37.928 & C-H rock due to alkanes \\
742.62 & 13.273 & 42.598 & C-H rock due to alkanes \\
858.35 & 22.36 & 34.492 & C-H oop due to aromatics \\
984.69 & 17.41 & 51.014 & C-H bend due to alkene \\
1070.53 & 11.776 & 71.187 & C-O stretch due to alcohol \\
1127.43 & 11.544 & 96.06 & C-O stretch due to alcohol \\
1280.78 & 11.332 & 138.509 & C-O stretch due to alcohol \\
1377.22 & 14.179 & 36.366 & C-H rock due to alkanes \\
1454.38 & 12.191 & 70.73 & C-H bend due to alkanes \\
1589.4 & 17.016 & 42.841 & C-C stretch in ring \\
1745.64 & 10.911 & 83.487 & C=O stretch due to cyclopentanone \\
2663.78 & 34.27 & 112.163 & OH stretch due to carboxylic acid \\
2855.71 & 10.923 & 108.588 & C-H stretch due to alkanes \\
2923.22 & 9.463 & 102.024 & C-H stretch due to alkanes \\
3509.6 & 18.049 & 109.697 & OH stretch due to alcohol or phenol \\
\hline
\end{tabular}

\section{Corrosion study}

Effect of FT gum on the corrosion of aluminum

Fig. 5 shows plots for the variation of weight loss with time for the corrosion of $\mathrm{Al}$ in $0.1 \mathrm{M}$ of $\mathrm{HCl}$ containing various concentrations of FT gum at 303 and 333 $\mathrm{K}$. From the plots, it was deduced that weight loss of Al increases with increase in the period of contact but decreases with increasing concentration of FT gum. These imply that FT gum retarded the corrosion of $\mathrm{Al}$ in solution of $\mathrm{HCl}$ and that FT gum is an adsorption inhibitor for the corrosion of $\mathrm{Al}$.

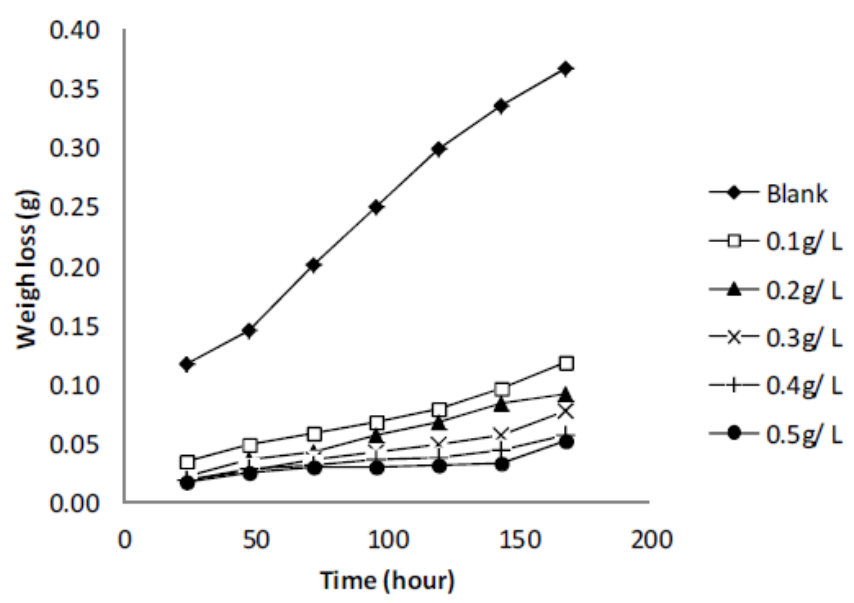

Figure 5. Variation of weight loss with time for the corrosion of $\mathrm{Al}$ in $\mathrm{HCl}$ containing various concentrations of FT gum at $303 \mathrm{~K}$.

Weight loss of $\mathrm{Al}$ was also found to decrease with increase in temperature which also suggests that the corrosion rate of $\mathrm{Al}$ in solutions of $\mathrm{HCl}$ containing FT gum decreases with increase in temperature. In view of the observed trend, values of corrosion rate of $\mathrm{Al}$ and inhibition efficiency of various concentrations of FT gum at 303 and $333 \mathrm{~K}$ were calculated and are recorded in Table 4 . The results 
obtained revealed that the inhibition efficiency of FT gum increases with increasing concentration and with increase in temperature at FT gum concentrations above $0.3 \mathrm{~g} / \mathrm{L}$. Based on literature, it can be inferred from the pattern of variation of inhibition efficiency with temperature, that two mechanisms of adsorption are possible. A physical adsorption mechanism applied when the inhibition efficiency decreases with increase in temperature, while a chemical adsorption mechanism applied when the inhibition efficiency decreases with increase in temperature [8]. From the calculated values of inhibition efficiency, it can be seen that the mechanisms of physical and chemical adsorption are clearly indicative at lower and higher concentrations of the inhibitors. Hence the mechanism of adsorption of FT gum on Al surface is concentration and temperature dependent.

Table 4. Corrosion rates for $\mathrm{Al}$, and inhibition efficiency and degree of surface coverage of $F T$ gum in $0.1 \mathrm{M} \mathrm{H}_{2} \mathrm{SO}_{4}$.

\begin{tabular}{ccccccc}
\hline $\mathbf{C}(\mathbf{g} / \mathbf{L})$ & $\begin{array}{c}\mathbf{C R}\left(\mathbf{g} / \mathbf{c m}^{2} / \mathbf{h}\right) \text { at } \\
\mathbf{3 0 3 ~ K}\end{array}$ & $\boldsymbol{\%} \mathbf{I}(\mathbf{3 0 3} \mathbf{~ K})$ & $\boldsymbol{\theta ( 3 0 3 ~ K )})$ & $\begin{array}{c}\mathbf{C R}\left(\mathbf{g} / \mathbf{c m}^{2} / \mathbf{h}\right) \\
\mathbf{a t ~ 3 3 3 ~ K}\end{array}$ & $\boldsymbol{\%} \mathbf{I}(\mathbf{3 3 3} \mathbf{~ K})$ & $\boldsymbol{\theta}(\mathbf{3 3 3} \mathbf{~ K})$ \\
\hline Blank & $1.63 \times 10^{-4}$ & & & $1.09 \times 10^{-4}$ & & \\
0.1 & $3.99 \times 10^{-5}$ & 75.53 & 0.7553 & $3.54 \times 10^{-5}$ & 67.51 & 0.6751 \\
0.2 & $3.66 \times 10^{-5}$ & 77.54 & 0.7754 & $2.74 \times 10^{-5}$ & 74.88 & 0.7488 \\
0.3 & $3.24 \times 10^{-5}$ & 80.10 & 0.8010 & $2.29 \times 10^{-5}$ & 78.98 & 0.7898 \\
0.4 & $2.74 \times 10^{-5}$ & 83.20 & 0.8320 & $1.67 \times 10^{-5}$ & 84.71 & 0.8471 \\
0.5 & $2.41 \times 10^{-5}$ & 85.21 & 0.8521 & $1.55 \times 10^{-5}$ & 85.80 & 0.8580 \\
\hline
\end{tabular}

\section{Kinetic study}

Corrosion of most metals including aluminum has been confirmed to be a first order reaction [22]. Hence the rate of corrosion can be represented as follows [23],

$$
-\frac{d[A l]}{[A l]}=k_{1} d t
$$

where $[\mathrm{Al}]$ is the concentration of $\mathrm{Al}, \mathrm{k}_{1}$ is the first order rate constant and $\mathrm{t}$ is the time or period of contact. Assuming the concentration of $\mathrm{Al}$ at time, $\mathrm{t}=0$ is denoted as $[\mathrm{Al}]_{0}$ at time , $\mathrm{t}=0$ and at some other time, ' $\mathrm{t}$ ' as $[\mathrm{Al}]$. Also, if $\mathrm{x} \mathrm{g}$ of $\mathrm{Al}$ have reacted after time, $\mathrm{t}$, then the concentration of $\mathrm{Al}$ at this time will be given as $([\mathrm{Al}]-\mathrm{x})$. Integration of equation 4 within the limit, $[\mathrm{Al}]_{0}$ and $([\mathrm{Al}]-\mathrm{x})$ yields equation 5 and upon simplification, equations 6 and 7 were obtained

$$
\begin{aligned}
& -\log \left(\frac{[\mathrm{Al}]_{0}-x}{[\mathrm{Al}]_{0}}\right)=\frac{k_{1} t}{2.303} \\
& -\log \left([\mathrm{Al}]_{0}-\mathrm{x}\right)=\mathrm{k}_{1} \mathrm{t} / 2.303-\log [\mathrm{Al}]_{0} \\
& -\log (\text { weight } \operatorname{loss})=\mathrm{k}_{1} \mathrm{t} / 2.303 \quad-\log [\mathrm{Al}]_{0}
\end{aligned}
$$




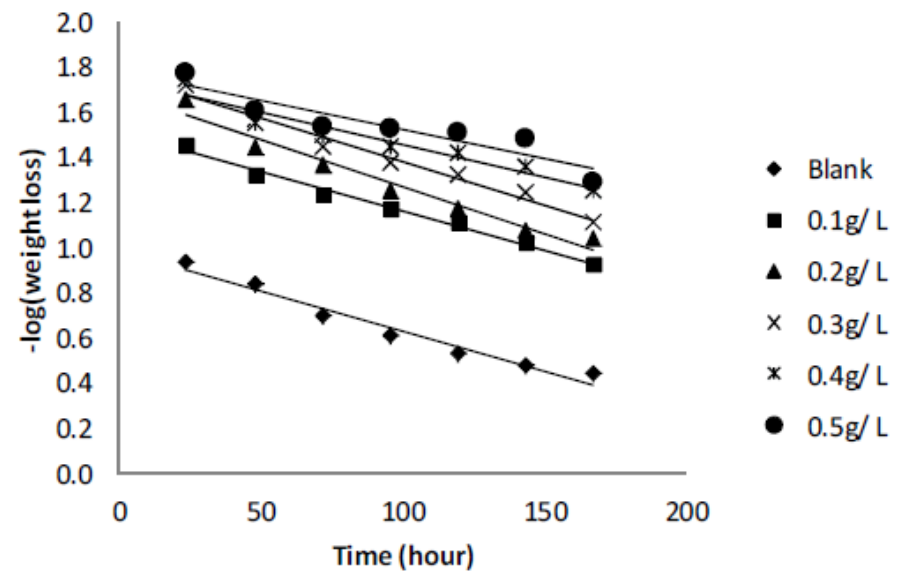

Figure 6. Variation of $-\log$ (weight loss) with time for the corrosion of $\mathrm{Al}$ in $0.1 \mathrm{M} \mathrm{HCl}$ containing various concentrations of FT gum at $303 \mathrm{~K}$.

Table 5. Kinetic parameters for the corrosion of $\mathrm{Al}$ in $0.1 \mathrm{M} \mathrm{HCl}$ containing various concentrations of FT gum.

\begin{tabular}{ccccccc}
\hline $\mathbf{T}(\mathbf{K})$ & $\mathbf{C}(\mathbf{g} / \mathbf{L})$ & slope & intercept & $\mathbf{k}_{\mathbf{1}}$ & $\mathbf{R}^{2}$ & $\mathbf{t}_{\mathbf{1} / 2}$ (hour) \\
\hline & Blank & 0.0036 & 0.9860 & 0.0083 & 1 & 0.9634 \\
& 0.1 & 0.0035 & 1.5086 & 0.0081 & 2 & 0.9883 \\
$\widetilde{\tilde{m}}$ & 0.2 & 0.0042 & 1.6854 & 0.0097 & 2 & 0.9612 \\
& 0.3 & 0.0039 & 1.7691 & 0.0090 & 2 & 0.9752 \\
& 0.4 & 0.0029 & 1.7444 & 0.0067 & 2 & 0.9231 \\
& 0.5 & 0.0026 & 1.7751 & 0.0060 & 2 & 0.8451 \\
& Blank & 0.0028 & 0.6843 & 0.0064 & 1 & 0.9377 \\
& 0.1 & 0.0031 & 1.3790 & 0.0071 & 2 & 0.9718 \\
$\widetilde{ల}$ & 0.2 & 0.0030 & 1.3945 & 0.0069 & 2 & 0.9534 \\
& 0.3 & 0.0028 & 1.3919 & 0.0064 & 2 & 0.9080 \\
& 0.4 & 0.0021 & 1.4304 & 0.0048 & 2 & 0.9069 \\
& 0.5 & 0.0020 & 1.4659 & 0.0046 & 3 & 0.9403 \\
\hline
\end{tabular}

From equation 7 , a plot of $-\log ($ weight loss) versus time should be a straight line with slope and intercept equal to $\mathrm{k}_{1} / 2.303$ and $\log [\mathrm{Al}]_{0}$, respectively. Fig. 6 presents plots for the variation of $-\log$ (weight loss) versus time for the corrosion of $\mathrm{Al}$ in solutions of $\mathrm{HCl}$ (plots obtained at $333 \mathrm{~K}$ are not shown). Values of $\mathrm{R}^{2}$, slopes and $\mathrm{k}_{1}$ deduced from the plots are presented in Table 5. The half-life of a first order reaction $\left(t_{1 / 2}\right)$ is related to the rate constant according to the following equation [22],

$$
\frac{t_{1}}{2}=\frac{0.6930}{k_{1}}
$$

From the results obtained (Table 5), it is evident that the half-life for the inhibited reactions of $\mathrm{Al}$ in solutions of $\mathrm{HCl}$ is higher than those obtained for the blank indicating that FT gum has the tendency to increase the half-life of aluminum in solutions of $\mathrm{HCl}$. 


\section{Effect of temperature}

Effect of temperature on the adsorption of FT gum on mild steel was studied using the logarithm form of the Arrhenius equation (Equation 8) [24]

$$
\log \frac{C R_{2}}{C R_{1}}=\frac{E_{a}}{2.303 R}\left(\frac{1}{T_{1}}-\frac{1}{T_{2}}\right)
$$

where $\mathrm{CR}_{1}$ and $\mathrm{CR}_{2}$ are the corrosion rates of aluminum in solution of $\mathrm{HCl}$ at the temperatures, $\mathrm{T}_{1}(303 \mathrm{~K})$ and $\mathrm{T}_{2}(333 \mathrm{~K})$, respectively, $\mathrm{E}_{\mathrm{a}}$ is the activation energy for the adsorption of FT gum on $\mathrm{Al}$ gum and $\mathrm{R}$ is the gas constant. Calculated values of the $E_{a}$ are shown in Table 6 . The activation energies are within the range of values expected for the mechanism of physical adsorption and tend to increase with increase in the concentration of FT gum. This implies that the mechanism of inhibition of $\mathrm{Al}$ corrosion by FT gum is concentration dependent. It is also significant to note that the activation energy calculated for the blank is higher than those calculated at FT gum concentrations of 0.1 to $0.3 \mathrm{~g} / \mathrm{L}$ and vice versa. This implies that less energy is needed for the adsorption of the inhibitor compared to the corrosion of the metal. On the other hand, above FT gum concentration of $0.3 \mathrm{~g} / \mathrm{L}$, calculated values of the activation energy were higher than the corresponding value for the blank but lower than the threshold value required for chemisorption. This suggests that at this concentration, the diffusion of the inhibitor's molecules (and not the energy of activation) may be the rate limiting process.

Table 6. Activation energy and heat of adsorption of various concentrations of FT gum on Al surface.

\begin{tabular}{ccc}
\hline $\mathbf{C}(\mathbf{g} / \mathbf{L})$ & $\mathbf{E}_{\mathbf{a}}(\mathbf{k J} \mathbf{J} \mathbf{m o l})$ & $\mathbf{Q}_{\text {ads }}(\mathbf{k J} / \mathbf{m o l})$ \\
\hline Blank & 11.22 & \\
0.1 & 3.32 & 8.31 \\
0.2 & 8.13 & 3.08 \\
0.3 & 9.73 & 1.45 \\
0.4 & 13.90 & -2.35 \\
0.5 & 12.41 & -1.00 \\
\hline
\end{tabular}

\section{Thermodynamics and adsorption considerations}

Adsorption of FT gum on Al surface can be exothermic or endothermic depending on the reaction condition, the nature of FT gum's molecules and the mechanism of reaction. In order to calculate the heat of adsorption of FT gum on Al surface, an established thermodynamic equation was used [25]:

$$
Q_{a d s}=2.303 R\left(\frac{\theta_{2}}{1-\theta_{2}}-\frac{\theta_{1}}{1-\theta_{1}}\right) \times\left(\frac{T_{1} \times T_{2}}{T_{2}-T_{1}}\right)
$$

where $Q_{a d s}$ is the heat of adsorption of FT gum on Al surface, $\theta_{1}$ and $\theta_{2}$ are the degrees of surface coverage of the inhibitor at the temperatures, $T_{1}$ and $T_{2}$ (where $\mathrm{T}_{2}>\mathrm{T}_{1}$ ) and $\mathrm{R}$ is the gas constant. Calculated values of $\mathrm{Q}_{\mathrm{ads}}$ (Table 6) reflected endothermic reaction at FT gum concentrations of 0.1 to $0.3 \mathrm{~g} / \mathrm{L}$, but an exothermic one at concentrations above $0.3 \mathrm{~g} / \mathrm{L}$. This suggests that, above a 
critical concentration of $0.3 \mathrm{~g} / \mathrm{L}$, the mechanism of inhibition of $\mathrm{Al}$ corrosion by FT gum is altered between physisorption to chemisorption.

The adsorption characteristics of an organic corrosion inhibitor can be studied using the adsorption isotherm, whose general form can be written as follows [26],

$$
\mathrm{f}(\theta, \mathrm{x}) \exp (-2 \mathrm{a} \theta) \quad=\quad \mathrm{bC}
$$

where $f(\theta, x)$ is the configurational factor which depends upon the physical model and the assumptions underlying the derivation of the isotherm, $\theta$, the surface coverage, $\mathrm{C}$, the inhibitor concentration in the electrolyte, ' $\mathrm{X}$ ' is the size factor ratio, ' $a$ ' is the molecular interaction parameter and ' $b$ ' is the equilibrium constant of the adsorption process. In this study, calculated values of $\theta$ at various concentrations of the inhibitor were fitted into various adsorption isotherms including Langmuir, Temkin, Freundlich, Flory-Huggins, Bockris-Swinkels and Frumkin isotherms. The test indicated that the adsorption of FT gum best fitted the Langmuir and Frumkin adsorption isotherms.

The Langmuir adsorption isotherm relates the degree of surface coverage to the concentration of the inhibitor according to the following equation [27],

$$
\theta=\frac{b c}{(1+b c)}
$$

where $\theta$ is the degree of surface coverage of the inhibitor, $\mathrm{C}$ is the concentration of the inhibitor in the bulk electrolyte and $b$ is the adsorption equilibrium constant. Simplification of equation 11 yields equation 12 and from the logarithm of both sides of equation 12, equation 13 was obtained

$$
\begin{aligned}
\theta+\theta \mathrm{bc} & =\mathrm{bc} \\
\log \left(\frac{c}{\theta}\right) & =\log \mathrm{C}-\log \mathrm{b}
\end{aligned}
$$

Plots of $\log \left(\frac{c}{\theta}\right)$ versus logb gave straight lines and values of logb were estimated from intercepts of the plots (Fig.7). Also values of $\mathrm{R}^{2}$ were very close to unity but slope values were not equal to unity as expected in the Langmuir model indicating the existence of interaction between the inhibitor's molecules.

In order to account for the existence of molecular interaction, the Frumkin adsorption model was found to be applicable to the adsorption of FT gum on Al surface. The Frumkin adsorption isotherm can be expressed as follows [28],

$$
\log \left(\frac{\theta}{1-\theta}\right)[C]=\log K+2 a \theta
$$




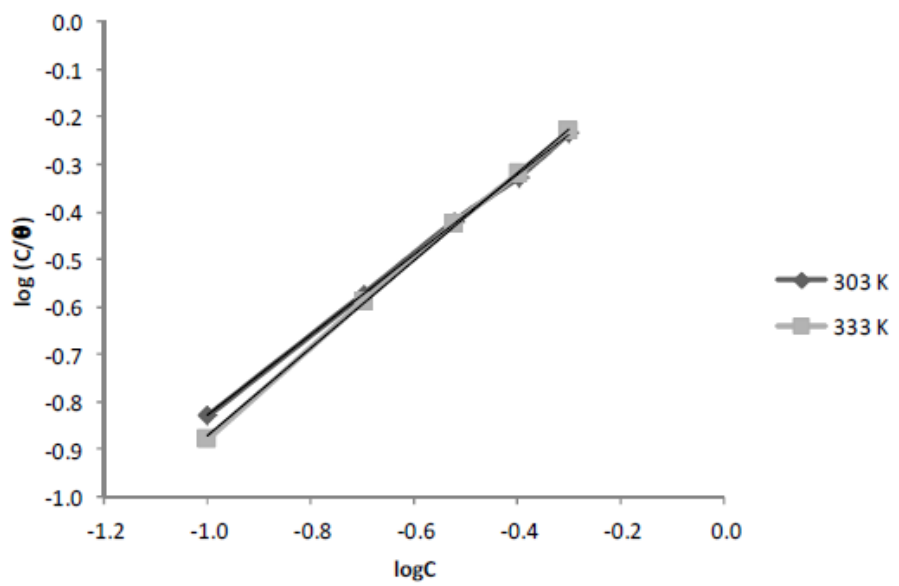

Figure 7. Langmuir isotherm for the adsorption of FT gum on Al surface.

From equation 14, a plot of $\left(\frac{\theta}{1-\theta}\right)[C]$ versus $\theta$ should be linear if Frumkin isotherm is obeyed. Fig. 8 shows the Frumkin isotherm for the adsorption of FT gum on Al surface. Frumkin adsorption parameters were also deduced from the plots and are presented in Table 7 . The results indicated that the interaction parameters are positive and tend to increase with increase in temperature, signifying the attractive behavior of the inhibitor and the possibility of chemisorption mechanism. The adsorption of FT gum on Al surface was also found to be consistent with the Dubinin-Radushkevich (D-RIM) adsorption isotherm, which can be expressed according to equation 12 [29],

$$
\ln (\theta)=\ln \left(\theta_{\max }\right)-\mathrm{a} \sigma^{2}
$$

where $\theta_{\max }$ is the maximum surface coverage and $\sigma$ is the polany potential and can be estimated from the following equation,

$$
\sigma=\operatorname{RT} \ln \left(1+\frac{1}{C}\right)
$$

Straight lines were obtained from plots of $\ln (\theta)$ versus $\sigma^{2}$ indicating the application of the D-RIM isotherm to the adsorption of FT gum on Al surface.

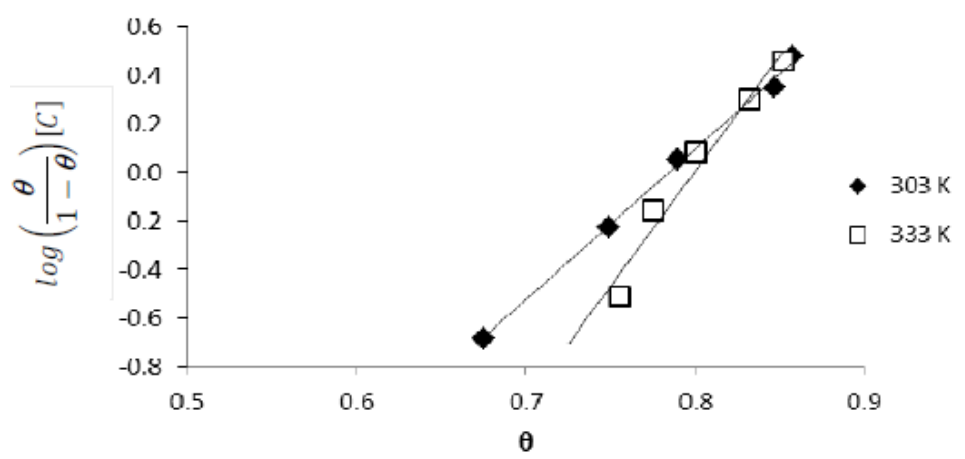

Figure 8. Frumkin isotherm for the adsorption of FT gum on $\mathrm{Al}$ surface. 
The constant ' $a$ ' and $\theta_{\max }$ were estimated from the slope and intercept of the plot, respectively. The results obtained revealed that the value of ' $\mathrm{a}$ ' at $303 \mathrm{~K}$ (i.e., $4 \mathrm{x}$ $\left.10^{-9}\right)$ is higher than the value at $333 \mathrm{~K}\left(7 \times 10^{-9}\right)$. Similar trend was observed for values of $\theta_{\max }$ at $303 \mathrm{~K}(66.64)$ and $333 \mathrm{~K}$ (63.38), respectively. It has been found that the constant, ' $\mathrm{a}$ ' is related to the mean adsorption energy (E) according to equation 17 [29]

$$
E=\frac{1}{\sqrt{2 a}}
$$

Table 7. Langmuir and Frumkin parameters for the adsorption of FT gum on Al surface.

\begin{tabular}{lcccccc}
\hline Isotherm & $\mathbf{T}(\mathbf{K})$ & slope & Intercept & $\mathbf{a}$ & $\mathbf{R}^{2}$ & $\Delta \boldsymbol{G}_{\text {ods }}^{0}\left(\frac{\mathrm{kJ}}{\mathrm{mol}}\right)$ \\
\hline Langmuir & 303 & 0.8462 & 0.0176 & & 0.9997 & -10.20 \\
& 333 & 0.9249 & 0.0517 & & 0.9995 & -11.42 \\
\multirow{3}{*}{ Frumkin } & 303 & 6.1905 & 4.8577 & 3.0953 & 0.9968 & -18.09 \\
& 333 & 9.4993 & 7.5962 & 4.7497 & 0.9672 & -37.34 \\
\hline
\end{tabular}

Also, several studies have shown that E value less than $8 \mathrm{~kJ} / \mathrm{mol}$ supports the mechanism of physical adsorption but $\mathrm{E}$ values greater than $8 \mathrm{~kJ} / \mathrm{mol}$ are consistent with the mechanism of chemisorption. Fig. 9 shows D-RIM isotherm for the adsorption of FT gum on Al surface. $\mathrm{R}^{2}$ values for the plots were 0.8450 and 0.9636 , while E values were 11.18 and $8.55 \mathrm{~kJ} / \mathrm{mol}$. From the calculated results, chemisorption mechanism is significant in the inhibition of the corrosion of Al by FT gum.

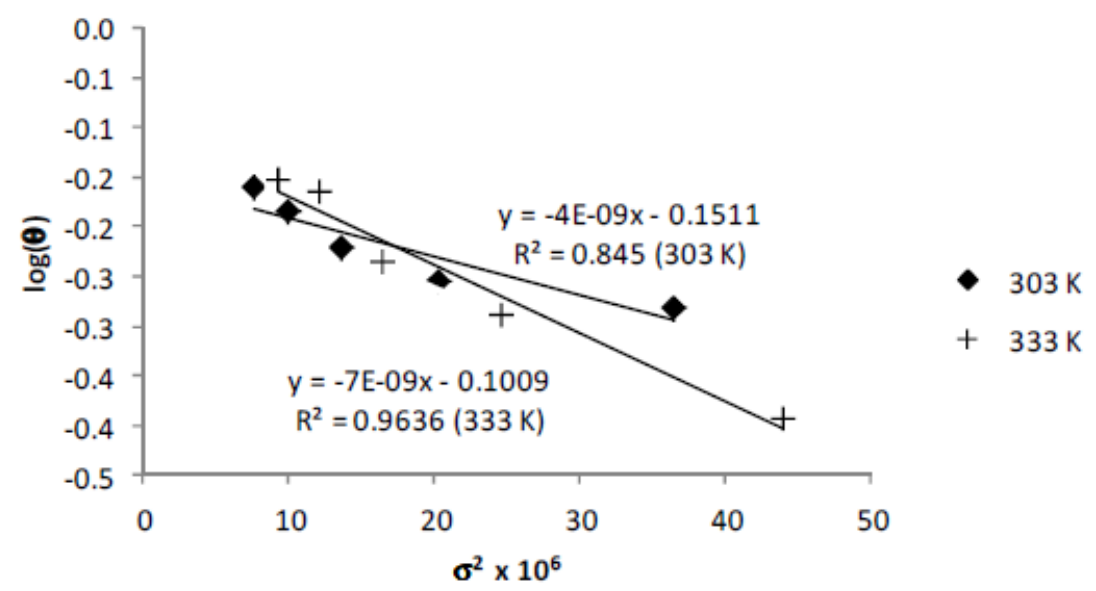

Figure 9. D-RIM isotherm for the adsorption of FT gum on $\mathrm{Al}$ surface.

The free energy of adsorption of FT gum on Al surface was estimated using the Gibb-Helmoltz equation, which relates the adsorption equilibrium constant with the free energy of adsorption as follows [30 - 31],

$$
b=\frac{1}{55.55} \exp \left(\frac{\Delta G_{\text {Gus }}^{\circ}}{R T}\right)
$$


where $\Delta G_{a d s}^{0}$ is the standard free energy of adsorption of FT gum on Al surface. Calculated values of $\Delta G_{\text {gds }}^{0}$ and 'b' deduced from Langmuir and Frumkin isotherms are presented in Table 7 . From the results obtained, the free energies are negative, indicating that the adsorption of FT gum on mild steel surface is spontaneous. However, while free energy values obtained from the Langmuir isotherm point towards a physisorption mechanism, those from the Frumkin isotherm reflect chemisorption mechanism. Hence the adsorption of FT gum is characterized by the initial mechanism of physical adsorption and is succeeded by chemical adsorption mechanism. Generally, values of $\Delta G_{a d s}^{0}$ below -20 $\mathrm{kJ} / \mathrm{mol}$ are consistent with the mechanism of charge transfer from the charged inhibitor to the charged metal surface, which supports physisorption, but $\Delta G_{\text {ads }}^{0}$ values close to or above - $20 \mathrm{~kJ} / \mathrm{mol}$ are consistent with the mechanism of chemical adsorption, which involves the transfer of electrons from the inhibitor's molecules to vacant d-orbital of the metal. From the present data, it is evident that the adsorption of FT gum on Al surface incorporated both mechanisms.

\section{Conclusions}

The results and findings of this study revealed that FT gum is a good inhibitor for the corrosion of $\mathrm{Al}$ in solution of $\mathrm{HCl}$. The inhibition potential of the gum is concentration and temperature dependent.

The adsorption of the gum is first order and is characterized by interchanging mechanism. Langmuir, Frumkin and Dubinin-Radushkevich adsorption isotherms are significant in describing the adsorption characteristics of the inhibitors.

In view of the above, the use of FT gum as an inhibitor for the corrosion of $\mathrm{Al}$ in acidic medium is hereby recommended.

\section{References}

1. El-Etre AY. Corros Sci. 2003;45:2485.

2. Bouklah M, Hammouti B. Port Electrochim Acta. 2006;24:457.

3. Singh DDN, Singh MM, Chaudhary RS, Agarwal CV. Electrochim Acta 1981;26:1051-1056.

4. Mears RB, Eldredge GG. Ind Eng Chem. 1945;37:736.

5. Singh DDN, Chaudhary RS, Prakash B, Agrawal CV. Br Corros J. 1979;14:235.

6. Metikos-Hukovic M, Babic R, Grubac Z. J Appl Electrochem. 1998;28:433.

7. Amin M, Khaled KF, Mohsen Q, Arida A. Corros Sci. 2010;52:1684.

8. Ramananda SM, Sharma V, Singh G. Port Electrochim Acta. 2011;29:405.

9. Oguzie EE, Onuchukwu AI, Okafor PC, Ebenso EE. Pigment Resin Tech. 2006;35:63.

10. A.M. Abdel-Gaber, B.A. Abd-El-Nabey, I.M. Sidahmed, et al. Corros Sci. 2006;48:2765.

11. Loto CA. Corros. Prev Control. 2001;48:38.

12. El-Etre AY. J Colloid Interf Sci. 2007;314:578. 
13. Loto CA. Corros. Prev Control. 2003;50:43.

14. El-Etre AY. Appl Surf Sci. 2006;252:8521.

15. Umoren SA, Obot IB, Ebenso EE, Egbedi NO. Port Electrochim Acta 2008;26:199.

16.. Eddy NO, Odiongenyi AO, Ameh PO, Ebenso EE. Int J Electrochem Sci. 2012;7:7425.

17. Eddy NO, Ameh PO, Gimba CE, Ebenso EE. Int J Electrochem Sci. 2011;6:5677.

18. Eddy NO, Ameh PO, Gimba CE, Ebenso EE. Int J Electrochem Sci. 2011;6:5815.

19. Dehri I, Ozcan M. Mater Chem Phys. 2006;98:316.

20. Ameh PO, Eddy NO, Gimba CE. Physiochemical and rheological studies on some natural polymers and their potentials as corrosion inhibitors. UK: Lambert Academic Publishing; 2012.

21. Carter SJ. Tutorial pharmacy: solution. Great Britain: Pitman Press; 2005.

22. Awe FE, Eddy NO. Amino acids as corrosion inhibitors: quantum and experimental studies. London, UK: Lambert Academic publishing; 2012.

23. Khaled KF. Corros Sci. 2010;52:2905.

24. Okafor PC, Ekpe UJ, Ebenso EE, et al. Bull Electrochem. 2005;21:347.

25. Elayyachy M, Hammouti B, El Idrissi A. Appl Surf Sci. 2005;249:176.

26. Morad MS, Kamal AM, El-Dean. Corros Sci. 2006;48:3398.

27. Behpour M, Ghoreishi SM, Khayatkashani M, Soltani N. Corros Sci. 2001;53:2489.

28. Gojic M. Corros Sci. 2002;43:919.

29. Noor EA. J Appl Electrochem. 2009;39:1465.

30. Dehri I, Ozcan M. Mater Chem Phys. 2006;98:316.

31. Popova A, Sokolova E, Raicheva S, Christov M. Corros Sci. 2003;45:33. 